\title{
Boundaries Matter - The Pros and Cons of Vertical Integration in BIM Implementation
}

\author{
Teemu Lehtinen \\ Enterprise Simulation Laboratory SimLab, \\ Department of Industrial Engineering and Management, \\ Aalto University School of Science, Espoo, Finland \\ teemu.lehtinen@aalto.fi
}

\begin{abstract}
Boundary spanning systemic innovations such as building information modeling (BIM) are difficult to implement. Literature suggests that vertical integration facilitates the implementation of systemic innovations. This study examines the role of vertical integration in the implementation of BIM as an example of a systemic innovation. It analyzes and compares two opposite case studies from the Finnish construction industry including a vertically integrated and a vertically disintegrated project networks. The findings propose that there are seven structurally relevant factors in BIM implementation; (1) management support, (2) coordination and control, (3) learning and experience, (4) technology management, (5) communication, (6) motivation, and (7) defining roles. Moreover, there are not only advantages but also disadvantages from vertical integration related to each of these implementation factors. Thus, in order to achieve as smooth and successful implementation as possible, managers should understand the impact of the network structure and plan the BIM implementation projects accordingly.
\end{abstract}

Keywords: Vertical integration, technology implementation, systemic innovation, building information modeling (BIM), the construction industry.

\section{$1 \quad$ Introduction}

Systemic innovations, such as building information modeling (BIM), that span over several organizational boundaries are extremely difficult to implement. As opposed to autonomous innovations that can be introduced as such without any major changes to the rest of the business system, systemic innovations require significant adjustments in other parts of the business system in order to be implemented successfully [1-3]. Many researchers have suggested that vertical integration (VI) facilitates the implementation of systemic innovations [1,4-7]. VI refers to a combination of several or all functions in the value chain under a single firm [8].

BIM is broadly a set of interacting policies, processes, and technologies generating a methodology to manage the essential building design and project data in digital format throughout the life cycle of a building between different stakeholders $[9,10]$. The acronym BIM can be used to refer to a product (building information model, a structured dataset describing a building), an activity (building information modeling, 
the act of creating a building information model), or a system (building information management, the business structures of work and communication that increase quality and efficiency) [11]. Over the years, other terms for BIM have also been used, such as building product modeling, product data modeling or virtual design and construction (VDC) $[9,12]$. In this study, BIM is defined broadly as a process and technology and the acronym refers to the term building information modeling as it seems to be gaining popularity in both industrial and academic circles [10].

BIM has been expected to bring significant improvements in the productivity of the construction industry since the 1980's but the implementation has been slower and more difficult than expected, largely due to its interorganizational and systemic nature [7,13-15]. At the same time, there has been an emerging trend of VI in the construction industry globally [16]. This paper aims to shed more light on the connection between BIM implementation and the organizational structure. The research question of this study is: what are the advantages and possible disadvantages of vertical integration in the implementation of BIM as an example of a systemic process innovation?

The empirical research of this study is based on a qualitative comparison of two opposite case studies from the Finnish construction industry; a vertically disintegrated project network and a vertically integrated project network. Both case studies included a single construction project in which BIM was being implemented. The qualitative data consists of project documentation, interviews, and observations. A theoretical model of the advantages and disadvantages of VI was first constructed based on the literature review. The model was later tested with the empirical data and refined into an improved model based on the analysis. Based on the findings, there are seven structurally relevant factors in BIM implementation with not only advantages but also disadvantages from VI. Thus, in order to achieve as smooth and successful implementation as possible, managers should understand the impact of the network structure and plan the BIM implementation projects accordingly.

\section{Advantages and Disadvantages of Vertical Integration in the Implementation of Systemic Innovations}

The literature on the advantages and disadvantages of VI was found on the general level and in the contexts of systemic innovations and the construction industry. Similarly, the literature related to the implementation of systemic innovations was found from three perspectives; the general implementation of organizational change, the implementation of collaborative technologies as an example of systemic process innovations, and the implementation of systemic innovations in the construction industry. A theoretical model was constructed as a synthesis of the literature review including these both perspectives. The constructed model consisted of six structurally relevant implementation factors which were (1) management support, (2) coordination and control, (3) learning and experience, (4) technology management, (5) communication, and (6) motivation. Each of these implementation factors included both advantages and disadvantages from VI. 
First factor, management support, emerged from the frameworks of Salminen [17] and Munkvold [18] which highlighted the importance of the management support for providing legitimacy for the implementation and gaining access to critical resources. The management support as such did not directly occur in the advantages and disadvantages of VI, however, as VI enables better control and coordination over several integrated units [19-21], top management support over all these units is easier. Mahoney [21] also brings up the benefit of audit and resource allocation in vertically integrated firms which relates to the more effective allocation of necessary resources between integrated units $[17,18]$. As a disadvantage, the extension of the management team and differing managerial requirements could lead to diverse management support over different integrated units and hinder the implementation [8,19].

Second factor, coordination and control, occurred often in the literature on the advantages and disadvantages of VI. Similarly, coordination and control activities are focal factors in implementation and change management. The advantages of VI are easier management of changing liability and contractual issues as there is no need to negotiate contracts $[15,20,22]$, the ability to make adaptations, adjustments, and redistribution of work timely and efficiently [1,4,15,23,24], and more stable relationships of different units which reduces uncertainty, boundary strength and enable the utilization of efficient processes [7,15,19,23-25]. The disadvantages are the inflexibility to change partners or processes when needed [8,19,20,23,24], broad management with differing managerial requirements which may be difficult to coordinate and control $[8,19,21]$, and the fact that systemic innovations may be too complex and large to manage under a single integrated firm [2,3].

Third factor, learning and experience, emerged from the literature of systemic innovations and the project-based construction industry. As a systemic process innovation is a collection of interconnected innovations related to the boundary spanning working practices of the whole business system, it cannot be implemented at once. Thus, in a project-based context the implementation occurs over several projects. Therefore, cumulative learning and experience is pivotal in the successful implementation of systemic process innovations. The advantages of VI are faster proceeding of learning and experience between integrated units $[6,26]$, the cumulative learning through the possibility to transfer the same organization and expertise from one project to another which reduces the organizational variety [7,23,24], and the facilitation of feedback loops and cross-pollination of ideas between different units $[15,23,24]$. The disadvantage is that VI may prevent access to external research, know-how, and relevant capabilities related to the systemic process innovation $[1,8,20,22]$.

Fourth factor, technology management, is derived from the frameworks of Munkvold [18] and Taylor [15]. Others have also mentioned the improved technological intelligence being related to VI $[1,8,20,22]$. The advantages of VI are the ability to ensure the interoperability of technology between integrated units and compatibility with existing technologies by selecting specific systems and software platforms $[15,18]$, the possibility to experiment with technology between integrated units [15], and the possibility to establish shared supportive infrastructure, guidelines, and feedback mechanisms for all integrated units $[18,27]$. The disadvantages are that VI may 
prevent the firm from perceiving technological advances related to the systemic process innovation in the market [1] or some relevant technological capabilities needed in the systemic process innovation may exist outside of the integrated firm [22].

Fifth factor, communication, emerged from the frameworks of Salminen [17] and Munkvold [18] in which the information sharing between all participants was emphasized. At the same time, communication was highly emphasized in the context of systemic innovations where a complete open exchange of information between different participants is essential. The advantages of VI are faster and more accurate information flow between integrated units $[1,8]$, the easier and safer exchange of information between integrated units [28], and more efficient communication through an internal coding system that can develop in integrated environment [21]. The disadvantage is the possible communication distortion which may be accidental or deliberate and arises from the increased hierarchical levels and spans of control [21].

Finally sixth factor, motivation, occurred in several implementation frameworks. To achieve successful implementation, different participants need to be motivated to implement and use the systemic innovation at hand. Salminen [17] also specified the need for change and goal setting as separate success factors which are closely related to motivation. The advantages of VI are the development of trust, solidarity, and communal spirit between integrated units [21], and the ability to understand shared interests and holistic goals which can motivate units that do not directly benefit from the systemic innovation [15]. The disadvantage is that the absence of internal competition decreases the overall motivation to change and implement new technologies [8].

\section{$3 \quad$ Methodology and Data}

The empirical research of this study is based on a comparison of two opposite case studies from the Finnish construction industry. The first case study was a unique university building project designed and constructed by a vertically disintegrated project network between 2003 and 2006. The second case study was a typical residential building project designed and constructed between 2007 and 2010 by a vertically integrated project network in which the owner, all the designers, and the main contractor were from the same organization.

The qualitative data consisted of project documentation, interviews, and observations. The project documentation was used as a basis for preparing for the interviews. The interviews included both single and group interviews. Overall, 46 individuals from 13 different organizations participated in the interviews. After the interviews, three full-day process simulation events were held to further validate the results. Altogether 66 individuals from 14 different organizations participated in the process simulation events. In addition to the empirical data from the project documentation and the interviews, these simulation events provided a rich source of observation data.

The empirical data were analyzed by using the constructed theoretical model. The model provided the categories for data coding and classification. The data reduction and analysis consisted of three phases. In the first phase, the transcribed data were 
gone through line by line by highlighting all the organizational structure related quotes concerning the BIM implementation. This resulted in total 148 quotes from the both case studies. At this phase, these quotes were also given a descriptive label. In the second phase, the collected quotes were classified with the six implementation factors in the constructed theoretical model. After the classification, there was a group of 12 quotes that did not fit into any of the six implementation factors. This group formed an additional implementation factor to the refined model. In the final phase of the analysis, the quotes under each implementation factors were compared with the pros and cons of VI in the constructed theoretical model. The conclusions were drawn based on the comparison.

\section{$4 \quad$ Findings}

The findings of this study propose that there are seven structurally relevant factors in BIM implementation; (1) management support, (2) coordination and control, (3) learning and experience, (4) technology management, (5) communication, (6) motivation, and (7) defining roles. There are also both advantages and disadvantages of VI related to each of these implementation factors.

The few findings related to the management support did not support the two advantages in the model, and thus further research is needed. These were the top management support over several integrated units at once, and the effective allocation of resources between integrated units. The findings supported the disadvantage whereby the broad management with differing managerial requirements may lead to diverse support over different units. But instead of differing managerial requirements, the different types of people as managers and varying economic situations of different integrated units emerged to be the sources of diverse management support which may have negative implications for the overall implementation of BIM.

The findings regarding the coordination and control supported the advantages related to the easier management of changing liability and contractual issues, and the ability to make adaptations, adjustments, and redistribution of work in a timely and efficient fashion which is facilitated especially by the shared location. The findings, however, did not support the advantage of stable relationships. Regarding the disadvantages, the findings supported all three disadvantages in the model except the inflexibility to change processes. Regarding the broad management, the findings highlighted the diverse geographical locations as a source of coordination and control difficulties. Finally, as BIM spans more broadly than just within the vertically integrated firm, both internal and external implementation need to be taken into account which makes the implementation more complex for vertically integrated firms.

In learning and experience, the findings supported all the advantages and the disadvantage in the model. Especially the advantage of cumulative learning and the disadvantage of not accessing relevant capabilities were highlighted. The findings did not provide any new perspective to the model regarding the learning and experience.

The findings related to the technology management supported all the advantages of VI in the original model. These were ensuring the interoperability through joint selection of software, experimenting with technology, and establishing shared supportive 
infrastructure. The findings, however, did not support the two disadvantages which stated that technological capabilities may exist outside, or that VI may prevent from perceiving technological advances in the market. These would require further research. In addition, the findings introduced an additional disadvantage of VI which was stiffness and slowness of a centralized IT department and bureaucracy. The inability to make quick adjustments in the IT environment of a vertically integrated firm may hinder the implementation of BIM.

In communication, the findings supported the advantages related to the faster and easier exchange of information between the integrated units but highlighted the shared location as a source. The findings, however, did not support the more efficient communication through a developed internal coding system. The findings also supported the disadvantage of increased hierarchical levels and spans of control which may lead to accidental or even deliberate communication distortion. Here, accidental communication distortion may arise because communication is taken for granted in a vertically integrated firm. Similarly, deliberate communication distortion may arise from "sibling envy" caused by the independence of different integrated units.

The findings regarding the motivation supported only the advantage of understanding the shared interests and holistic goals. The advantage of developing trust and solidarity, and the disadvantage of absent internal competition were not supported by the empirical data. The emergence of new work and the need to redistribute work in BIM implementation may cause conflicts of interests between different participants, and thus, decrease motivation. This issue seems to be easier to handle in a vertically integrated firm as understanding the shared interests and holistic goals can motivate those integrated units that do not directly benefit from BIM.

The findings also introduced the seventh additional structurally relevant factor that was not in the original model; defining roles. As an advantage, it is easier to define and fulfill the new roles needed in BIM implementation from the holistic perspective in a vertically integrated project network. The disadvantage is, however, that "buck passing" may emerge in vertically integrated firm which means that everything related to the implementation may be pushed to the new role, and thus, hindering the implementation.

\section{Conclusions}

The findings of this study introduced seven structurally relevant implementation factors with related advantages and disadvantages of vertical integration. These factors are (1) management support, (2) coordination and control, (3) learning and experience, (4) technology management, (5) communication, (6) motivation, and (7) defining roles. The findings related to the advantages and disadvantages in these factors both reinforced the previous knowledge and provided new knowledge to the field. Mainly, this study confirms that in addition to the expected benefits from VI in BIM implementation there are also many disadvantages from VI that may greatly hinder the implementation efforts. Some of the advantages and disadvantages in the original theoretical model could not be confirmed in the study but these could not, however, 
be challenged by the empirical data either, and therefore, they were kept in the improved theoretical model. In order to determine the significance of these unconfirmed issues, further research is needed.

According to the findings, the organizational structure of the project network does affect the implementation of BIM in both positive and negative ways. More specifically, vertically integrated project network has its advantages and disadvantages during the BIM implementation. Both advantages and disadvantages need to be taken into account in order to be able to implement BIM more smoothly and successfully at least in a vertically integrated project network. Thus, managers should understand how the network structure of their company and project network could influence the implementation efforts and embrace the advantages and try to overcome the disadvantages when implementing BIM and possibly other systemic process innovations.

There are some limitations to this study. First of all, the study investigated only two project networks and two separate implementation projects in the construction industry. The two opposite project networks, however, provided good insights into the focus of this study. However, more case studies targeting on different project networks and even other kinds of systemic innovations is needed. Second, some of the elements in the theoretical model could not be confirmed in the cases as they would have required more longitudinal research. As the overall BIM implementation requires several successive implementation projects, a further examination of successive projects within these same project networks might introduce interesting new insights to the model. Finally, the case studies were from the Finnish construction industry, and thus, the findings may not be generalizable to other countries. For example, the different industrial structures or cultural differences could affect the findings. Addressing these limitations would improve the generalizability of the findings.

\section{References}

1. Teece, D.J.: Firm Organization, Industrial Structure, and Technological Innovation. Journal of Economic Behavior \& Organization 31, 193-224 (1996)

2. De Laat, P.B.: Systemic Innovation and the Virtues of Going Virtual: The Case of the Digital Video Disc. Technology Analysis \& Strategic Management 11, 159-180 (1999)

3. Maula, M.V.J., Keil, T., Salmenkaita, J.-P.: Open Innovation in Systemic Innovation Contexts. In: Chesbrough, H., Vanhaverbeke, W., West, J. (eds.) Open Innovation: Researching a New Paradigm, pp. 241-257. Oxford University Press, New York (2006)

4. Armour, H.O., Teece, D.J.: Vertical Integration and Technological Innovation. The Review of Economics and Statistics 62, 470-474 (1980)

5. Chesbrough, H.W., Teece, D.J.: Organizing for Innovation: When Is Virtual Virtuous? Harvard Business Review 80, 127-135 (2002)

6. Langlois, R.N.: Transaction-Cost Economics in Real Time. Industrial and Corporate Change 1, 99-127 (1992)

7. Taylor, J.E., Levitt, R.: Understanding and Managing Systemic Innovation in ProjectBased Industries. In: Slevin, D., Cleland, D., Pinto, J. (eds.) Innovations: Project Research 2004. Project Management Institute, Newtown Square, pp. 1-17 (2004), http: / / crgp. stanford. edu/publications/bookchapters/TaylorLev itt.pdf (accessed July 15, 2011) 
8. Porter, M.E.: Competitive Strategy - Techniques for Analyzing Industries and Competitors. The Free Press, New York (1980)

9. Penttilä, H.: Describing the Changes in Architectural Information Technology to Understand Design Complexity and Free-Form Architectural Expression. Electronic Journal of Information Technology in Construction 11, 395-408 (2006)

10. Succar, B.: Building Information Modelling Framework: A Research and Delivery Foundation for Industry Stakeholders. Automation in Construction 18, 357-375 (2009)

11. National Institute of Building Sciences: United States National Building Information Modeling Standard, Version 1 - Part 1: Overview, Principles, and Methodologies, http: / /www.wbdg.org/pdfs /NBIMSv1_p1.pdf (accessed August 5, 2011)

12. Kunz, J., Fischer, M.: Virtual Design and Construction: Themes, Case Studies and Implementation Suggestions. CIFE Working Paper Number 97. Stanford University (2009)

13. Fischer, M., Kam, C.: PM4D Final Report: Case Study HUT-600. CIFE Technical Report Number 143, Stanford University (2002)

14. Taylor, J.E., Levitt, R.: Innovation Alignment and Project Network Dynamics: An Integrative Model for Change. Project Management Journal 38, 22-35 (2007)

15. Taylor, J.E.: Antecedents of Successful Three-Dimensional Computer-Aided Design Implementation in Design and Construction Networks. Journal of Construction Engineering and Management 133, 993-1002 (2007)

16. Cacciatori, E., Jacobides, M.G.: The Dynamic Limits of Specialization: Vertical Integration Reconsidered. Organization Studies 26, 1851-1883 (2005)

17. Salminen, A.: Implementing Organizational and Operational Change - Critical Success Factors of Change Management. Industrial Management and Business Administration Series 7 (2000)

18. Munkvold, B.E.: Implementing Collaboration Technologies in Industry: Case Examples and Lessons Learned. Springer, London (2003)

19. Blois, K.J.: Vertical Quasi-Integration. The Journal of Industrial Economics 20, 253-272 (1972)

20. Harrigan, K.R.: Formulating Vertical Integration Strategies. Academy of Management Review 9, 638-652 (1984)

21. Mahoney, J.T.: The Choice of Organizational Form: Vertical Financial Ownership Versus Other Methods of Vertical Integration. Strategic Management Journal 13, 559-584 (1992)

22. Krippaehne, R.C., McCullouch, B.G., Vanegas, J.A.: Vertical Business Integration Strategies for Construction. Journal of Management in Engineering 8, 153-166 (1992)

23. Winch, G.: The Construction Firm and the Construction Process: The Allocation of Resources to the Construction Project. In: Lansley, P., Harlow, P. (eds.) Managing Construction Worldwide: Productivity and Human Factors in Construction, vol. 2, pp. 967-975 (1987)

24. Winch, G.: The Construction Firm and the Construction Project: A Transaction Cost Approach. Construction Management and Economics 7, 331-345 (1989)

25. Williamson, O.E.: The Vertical Integration of Production: Market Failure Considerations. The American Economic Review 61, 112-123 (1971)

26. Langlois, R.N., Robertson, P.L.: Explaining Vertical Integration: Lessons from the American Automobile Industry. Journal of Economic History 49, 361-375 (1989)

27. Nadler, D.A.: Managing Organizational Change: An Integrative Perspective. Journal of Applied Behavioral Science 17, 191-211 (1981)

28. Gopalakrishnan, S., Bierly, P.: Analyzing Innovation Adoption Using a Knowledge-Based Approach. Journal of Engineering and Technology Management 18, 107-130 (2001) 